\title{
Gedragen gedragsverandering*
}

\author{
Lars Tummers
}

\section{Noodzaak tot gedragen gedragsverandering}

Het veranderen van gedrag is vaak noodzakelijk om maatschappelijke problemen aan te pakken. Als we willen dat burgers minder vaak in de schulden komen, moeten we analyseren hoe we deze burgers kunnen helpen om meer te sparen en minder uit te geven. Als we gezonder willen zijn, moeten we meer bewegen, minder suiker en vet eten, en al helemaal geen frisdrank meer drinken (Warburton, Nicol, \& Bredin, 2006; De Ruyter, Oldhof, Seidell, \& Katan, 2012). Als we willen dat mensen gaan stemmen bij verkiezingen - zelfs als het hard regent en zelfs als het verkiezingen zijn voor de Provinciale Staten - moeten we manieren bedenken om burgers toch naar de stembus te lokken. Inzichten uit de verschillende disciplines - zoals de economie en de psychologie - helpen om gedrag van mensen te veranderen.

Deze inzichten bieden nieuwe mogelijkheden voor de overheid als het gaat om gedragsverandering. Maar de overheid mag geen manipulator zijn die zonder draagvlak de nieuwste gedragstrucs toepast. De overheid heeft draagvlak nodig voor gedragsveranderingen. Hier komt de expertise van bestuurskundigen van pas. Bestuurskundig onderzoek naar bijvoorbeeld conflicten tussen managers en professionals (Noordegraaf \& Steijn, 2014) en weerstand bij overheidshervormingen (Kuipers et al., 2014) laat zien dat draagvlak voor verandering niet vanzelfsprekend is. Zo laat het bestuurskundige model van 'beleidsvervreemding' (Tummers, 2012; Van Engen, 2017) zien wat er gebeurt als publieke dienstverleners - zoals docenten - zich niet kunnen identificeren met overheidsbeleid. Als docenten beleidsvervreemding ervaren, kan dit leiden tot weerstand, sabotage, en zelfs stakingen.

In dit artikel voor Bestuurskunde - gebaseerd op mijn oratie - laat ik eerst zien welke beleidsinstrumenten de overheid heeft om gedragsverandering tot stand te brengen. Hierna introduceer ik een model van gedragen gedragsverandering, waarbij ik expliciet het belang van draagvlak aangeef. Het model van gedragen gedragsverandering laat zien hoe we op een bredere manier gedragsinterventies van de overheid kunnen analyseren. Tot slot geef ik aan hoe ik de komende jaren

* Prof. dr. L.G. Tummers werkt als hoogleraar Bestuurs- en Organisatiewetenschap, in het bijzonder Publiek Management en Gedrag, bij het departement Bestuurs- en Organisatiewetenschap (USBO) van de Universiteit Utrecht. Dit stuk is een verkorte versie van mijn oratie, uitgesproken op 15 maart 2019. Deze publicatie is mede mogelijk gemaakt door een beurs van de Nederlandse Organisatie voor Wetenschappelijk Onderzoek (NWO, 016.VIDI. 185.017). Furthermore, this work was supported by the National Research Foundation of Korea Grant, funded by the Korean Government (NRF-2017S1A3A2067636). 
via samenwerking met de praktijk en binnen de wetenschap verder wil werken aan onderzoek naar gedragen gedragsverandering.

\section{Gedragsverandering door de overheid}

\section{Traditionele beleidsinstrumenten}

De overheid heeft verschillende instrumenten om gedragsverandering tot stand te brengen. Traditioneel onderscheiden bestuurskundigen de wortel, de zweep en de preek (Bovens et al., 2017).

De wortel staat voor een economische aanpak: om gedrag te veranderen moet je prikkels geven. Zo kreeg je vroeger veel subsidie als je een elektrische auto kocht. Veel mensen maakten hier gebruik van. Als je deze subsidievoorwaarden aanpast, dan verandert het gedrag. De verkoop van dure elektrische auto's zoals Tesla's daalde bijvoorbeeld met 99\% toen in 2019 de subsidievoorwaarden minder gunstig werden (Kalse, 2019). Naast de wortel bestaat traditioneel de zweep. Als de wortel staat voor de econoom - beïnvloeden via prikkels - dan staat de zweep voor de jurist: je verandert gedrag via geboden en verboden. Een rookverbod in cafés, maar ook de leerplicht tot 18 jaar zijn voorbeelden waarin de overheid de spreekwoordelijke zweep gebruikt om gedrag van burgers te sturen. Het derde beleidsinstrument is de preek. Het prototypische voorbeeld van de preek zijn de communicatiecampagnes van het Rijk, bijvoorbeeld NIX18 over niet roken en drinken tot je 18de.

\section{Een nieuw beleidsinstrument door inzichten uit de psychologie}

De wortel, zweep en preek gaan uit van een rationeel beslissende burger. Maar mensen beslissen niet volledig rationeel, zoals we weten uit het werk van Herbert Simon $(1955,1978)$. Als je gedrag wilt veranderen, kun je hiervan gebruikmaken. Thaler en Sunstein beschrijven in hun boek 'Nudge' (2008) een nieuwe manier van gedragsverandering die niet uitgaat van rationaliteit. Een nudge is een manier om gedrag te veranderen zonder opties te verbieden of de kosten van opties sterk te veranderen. Nudges verbieden dus geen opties (zoals bij de zweep) en veranderen de kosten van een keuze niet substantieel (zoals bij de wortel). Het is ook anders dan een preek, omdat nudges niet uitgaan van rationeel beslissende burgers.

Ik merk hierbij wel op dat de verschillen zo duidelijk benadrukt kunnen worden, maar dat er in de werkelijkheid wel overlappen bestaan. Zo is 10 cent voor een tas bij de bakker aan de ene kant een negatieve economische prikkel, maar zou je ook kunnen beargumenteren dat deze prikkel zo klein is dat het juist een nudge is.

Tabel 1 geeft een overzicht weer van de vier beleidsinstrumenten.

\section{Weerstand tegen gedragsverandering}

Een voorbeeld van nudge is het duidelijk maken van sociale normen, bijvoorbeeld met stellingen als ' 90 procent van de mensen betaalt hun belastingen op tijd', wat ervoor zorgt dat meer mensen hun belastingen op tijd betalen (Hallsworth, List, 
Tabel 1 Duwtje/nudge als vierde beleidsinstrument voor gedragsverandering

\begin{tabular}{|c|c|c|c|c|}
\hline & I. Wortel & 2. Zweep & 3. Preek & $\begin{array}{l}\text { 4. Duwtjel } \\
\text { nudge }\end{array}$ \\
\hline Discipline & Economie & Rechten & $\begin{array}{l}\text { Communicatie- } \\
\text { wetenschap }\end{array}$ & Psychologie \\
\hline Verandering via & Prikkels & $\begin{array}{l}\text { Geboden en } \\
\text { verboden }\end{array}$ & Overtuiging & $\begin{array}{l}\text { Keuze-architec- } \\
\text { tuur }\end{array}$ \\
\hline Slogan & $\begin{array}{l}\text { Beloon gewenst } \\
\text { gedrag! }\end{array}$ & $\begin{array}{l}\text { Maak ongewenst } \\
\text { gedrag illegaal! }\end{array}$ & $\begin{array}{l}\text { Vertel wat } \\
\text { gewenst gedrag } \\
\text { is! }\end{array}$ & $\begin{array}{l}\text { Maak gewenst } \\
\text { gedrag gemakke- } \\
\text { lijk! }\end{array}$ \\
\hline Voorbeeld & $\begin{array}{l}\text { Subsidieer elektri- } \\
\text { sche auto }\end{array}$ & $\begin{array}{l}\text { Verbied wapenbe- } \\
\text { zit }\end{array}$ & NIXI8 & $\begin{array}{l}\text { Standaard-leenbe- } \\
\text { drag aanpassen }\end{array}$ \\
\hline
\end{tabular}

Metcalfe, \& Vlaev, 2017). Een ander voorbeeld van een nudge is het aanpassen van de standaard. Het slim zetten van standaarden werkt vaak (Jachimowicz, Duncan, Weber, \& Johnson, 2019), maar het vereist wel draagvlak, zeker als je afhankelijk bent van andere partijen.

Het belang van draagvlak wordt duidelijk als we kijken naar het veranderen van een standaard in de bankensector (Willis, 2013). In de Verenigde Staten kun je een betaling doen terwijl er eigenlijk te weinig geld op je rekening staat. Dit staat bekend als de 'rekening-courantdekking'. Stel dat je een kopje koffie wilt kopen, maar je hebt te weinig op je rekening staan. Dan kun je dat kopje koffie toch betalen via deze dekking. Je betaalt alleen wel een boete. Daarmee kost je kopje koffie geen 3 dollar, maar bijvoorbeeld 28 dollar, omdat je 25 dollar boete betaalt.

Deze rekening-courantdekking is winstgevend voor banken. Vooral mensen met lage inkomens hoesten deze winst op. Zij hebben vaak net te weinig geld op hun rekening staan. De Amerikaanse overheid wilde dit aanpassen. Het veranderen van de standaard leek een uitstekende manier. In 2010 verplichtte ze daarom de banken om als standaard geen rekening-courantdekking te geven. Beleidsmakers hadden echter het draagvlak bij de banken overschat. De banken waren niet bereid deze winstgevende activiteit op te geven. Ze probeerden klanten juist weer een rekening-courantdekking te geven. Klanten hoefden bijvoorbeeld alleen maar op een knop te drukken bij de pinautomaat om de standaard aan te passen. Ongeveer 50 procent van de klanten meldde zich actief aan voor de rekening-courantdekking. Dit waren vooral mensen voor wie deze rekening-courantdekking veel geld kostte, omdat ze er vaak gebruik van maken: mensen met lage inkomens. De interventie van de overheid was volledig mislukt (Willis, 2013). De kosten voor de rekening-courantdekking zijn zelfs omhooggegaan.

\section{Model voor gedragen gedragsverandering}

Het voorbeeld van de bankensector laat zien dat de overheid bij het inzetten van beleidsinstrumenten voor gedragsverandering rekening moet houden met draagvlak. De overheid moet zorgen voor gedragen gedragsverandering. Ik maak hierbij 
Tabel 2 Vijf criteria om te meten of er sprake is van gedragen gedragsverandering

\begin{tabular}{|c|c|c|}
\hline Focus & Criterium & Voorbeeldvraag \\
\hline \multirow[t]{2}{*}{ Gedragsverandering } & $\begin{array}{l}\text { Effectieve gedragsver- } \\
\text { andering }\end{array}$ & $\begin{array}{l}\text { I. Zorgt de interventie voor gedragsverande- } \\
\text { ring en wat zijn bijeffecten? }\end{array}$ \\
\hline & $\begin{array}{l}\text { Efficiënte gedragsver- } \\
\text { andering }\end{array}$ & $\begin{array}{l}\text { 2. Wegen de kosten van de gedragsverandering } \\
\text { op tegen de opbrengsten? }\end{array}$ \\
\hline \multirow[t]{3}{*}{ Gedragen } & Politiek gedragen & $\begin{array}{l}\text { 3. Steunen politieke partijen de gedragsveran- } \\
\text { dering? }\end{array}$ \\
\hline & $\begin{array}{l}\text { Organisatorisch gedra- } \\
\text { gen }\end{array}$ & 4. Steunen organisaties de gedragsverandering? \\
\hline & Persoonlijk gedragen & $\begin{array}{l}\text { 5. Steunen publieke dienstverleners en burgers } \\
\text { de gedragsverandering? }\end{array}$ \\
\hline
\end{tabular}

een onderscheid tussen - simpel gesteld - drie soorten draagvlak: politiek draagvlak, draagvlak bij organisaties en persoonlijk draagvlak. Het bijbehorende acroniem is dan POP, een afkorting voor populair. Als de gedragsverandering zowel politiek, organisatorisch als persoonlijk gedragen is, is deze dus POPulair.

Hoe weet je of er sprake is van gedragen gedragsverandering? Je kan - grofweg via vijf criteria meten of hier sprake van is. Dit staat weergegeven in tabel 2. Er zijn natuurlijk meerdere criteria te verzinnen die van belang zijn (zie bijvoorbeeld Hemerijck, 2003; Hood, 1991; March \& Olsen, 1989), maar zoals Goldstein en Gigerenzer (2011, p. 392) stellen: 'The beauty of simple models is that one can easily discover their limits, that is, their boundary conditions, which in turn fosters clarity and progress.' Ik heb er daarom expliciet voor gekozen om het model simpel te houden.

Om deze vijf criteria te illustreren gebruik ik een concrete casus. In een recent artikel in het prestigieuze medische tijdschrift The Lancet testen Hallsworth et al. (2016) de kracht van sociale normen om ervoor te zorgen dat artsen minder antibiotica voorschrijven. Dit kan een groot maatschappelijk probleem in veel landen - antibioticaresistentie - verminderen. De onderzoekers identificeerden huisartsen die vaker dan gemiddeld antibiotica voorschreven. Deze artsen schrijven waarschijnlijk te veel voor. Ze verdeelden deze veel-voorschrijvende huisartsen in twee groepen: een groep die een brief ontving en een groep die niets ontving. In de brief stond dat de huisartsenpraktijk meer antibiotica voorschreef dan 80 procent van de collega's in de lokale omgeving. Dit is de sociale norm: je geeft aan wat de anderen doen. De artsen ontdekten zo: ik schrijf meer antibiotica voor dan mijn collega's en wijk daarmee af van de norm. De brief zorgde voor het gewenste effect. De ongeveer 3.000 artsen die de brief ontvingen, verstrekten daarna ongeveer 70.000 minder antibioticakuren in een half jaar.

De vijf criteria kunnen we toepassen op de studie uit The Lancet. Het eerste criterium gaat over de effectiviteit van de verandering. Als je effectiviteit ziet als min- 
der voorgeschreven antibioticakuren, is de studie een eclatant succes. Maar het gaat niet alleen om de directe doelen, maar ook om neveneffecten. Stel dat uw huisarts, vlak voor uw bezoek, een brief had ontvangen dat zij meer voorschreef dan andere praktijken. Uw huisarts schrijft u vervolgens geen antibiotica voor, deels ingegeven door die brief. $U$ wordt zieker en $u$ belandt in het ziekenhuis. Als $\mathrm{u}$ antibiotica had gekregen, was dit niet gebeurd. In hoeverre was de studie dan een succes? Er zijn meerdere effecten mogelijk, en het ontkennen of niet meten hiervan geeft een vertekend beeld. Het tweede criterium gaat over de doelmatigheid van de interventie. Wegen de kosten van de gedragsverandering op tegen de opbrengsten? In dit voorbeeld zijn de kosten redelijk beperkt. De onderzoekers stuurden alleen een brief, wat leidde tot veel minder antibioticagebruik.

De laatste drie criteria gaan over het draagvlak. De eerste vraag is of het politiek haalbaar is om dit soort gedragsveranderingen door te voeren. Vinden politieke partijen het passend dat de artsen door psychologische 'trucs' minder antibiotica voorschrijven? Het gevaar van manipulatie ligt op de loer. Naast politieke haalbaarheid gaat het om uitvoerbaarheid bij organisaties. Kunnen en willen publieke en private organisaties de interventie uitvoeren? Het is onduidelijk in hoeverre verschillende publieke en private organisaties deze sociale norminterventie steunen. Naast politiek en organisatorisch draagvlak moet er ook draagvlak zijn bij de individuele professional en burger. Zo wisten de artsen en patiënten in het Lancet-onderzoek niet dat ze meededen aan een experiment. De onderzoekers hebben geen toestemming gevraagd aan artsen of patiënten, omdat dit de effecten teniet zou kunnen doen. Vinden we dit acceptabel? We willen toch weten wat er met ons gebeurt, zeker als het over ons eigen lichaam gaat?

Het model van gedragen gedragsverandering laat zien hoe we op een bredere manier gedragsinterventies van de overheid kunnen analyseren. De vijf criteria kun je toepassen op concrete cases. We kunnen hierdoor op een bredere manier gedragsverandering door de overheid analyseren. Zo kijken we niet alleen naar de effectiviteit, maar ook naar efficiëntie en steun bij politici, organisaties en burgers.

\section{Onderzoek naar gedragen gedragsverandering}

De komende jaren wil ik door samenwerking met de praktijk en binnen de wetenschap verder werken aan onderzoek naar gedragen gedragsverandering.

\section{Samenwerken met de praktijk}

Ten eerste is het mijn overtuiging dat de bestuurskunde, inclusief de gedragsbestuurskunde (Grimmelikhuijsen, Jilke, Olsen, \& Tummers, 2017; Tummers, Olsen, Jilke, \& Grimmelikhuijsen, 2016), beter moet samenwerken met de praktijk (Egeberg, 1994; Moynihan, 2018). Dit betekent dus dat wij als wetenschappers uit onze ivoren toren moeten komen en moeten samenwerken. Maar het betekent ook dat samenwerkingspartners uit de praktijk moeten inzien dat als je samenwerkt met wetenschappers je soms concessies moet doen aan snelheid om 
de kwaliteit van onderzoek te vergroten. Geen 'quick and dirty' onderzoek, maar 'slow and clean'. Graag werk ik samen met maatschappelijke partners om te analyseren hoe we kunnen komen tot gedragen gedragsverandering. Dit betekent: experimenteren in het veld via veldexperimenten, want we weten niet of iets werkt voordat we het goed testen in specifieke contexten (bijvoorbeeld Bronkhorst, Tummers, \& Steijn, , 2018).

\section{Samenwerking binnen de wetenschap}

Ten tweede moeten we meer samenwerken met collega-wetenschappers uit andere disciplines. Een voorbeeld verduidelijkt dit. Zo werken we in het consortium Prompted Rationality (www.promptedrationality.com) samen met onder anderen bestuurskundigen, psychologen, design wetenschappers, economen, sociologen en juristen. We willen een verbinding leggen tussen inzichten over empathie en inzichten over gedragsverandering. Veel gedragsinterventies zijn tot nu toe erg individualistisch. Zo krijgt $u$ een boete als $u$ door rood rijdt, kunt $u$ subsidie krijgen op uw zonnepanelen, en wordt $u$ genudged om donor te worden. Er is maar weinig aandacht voor het feit dat de mens zich kan inleven in de ander. Empathie is inlevingsvermogen, kunnen voelen wat de ander voelt. Neuropsychologisch onderzoek naar spiegelneuronen laat dit zien (Gallese \& Goldman, 1998; Iacoboni, 2009). Spiegelneuronen worden actief als je iemand anders iets ziet doen. Kunnen we mensen minder prikkelen via individuele instrumenten (bijvoorbeeld: als u geld geeft aan oorlogsslachtoffers kunt u dit van de belasting aftrekken) en juist meer prikkelen door in te spelen op hun empathie (bijvoorbeeld: probeer $\mathrm{u}$ voor te stellen dat $\mathrm{u}$ zelf in een oorlog terechtkomt)? Misschien is dit wel veel effectiever, voelen mensen zich autonomer als ze hierover beslissen, en is er ook meer draagvlak voor. Ik wil met anderen analyseren of we de neuropsychologische inzichten over empathie kunnen gebruiken om nieuwe instrumenten voor gedragsverandering te ontwikkelen.

\section{Conclusie}

Het model voor gedragen gedragsverandering helpt hopelijk om orde te scheppen in de complexe werkelijkheid. Nieuwe theorieontwikkeling - zoals naar interventies met een nadruk op empathie - en meer gebruik van veldexperimenten als methode zijn noodzakelijk om te bestuderen hoe we kunnen komen tot gedragen gedragsverandering. Door samenwerking met wetenschap en praktijk op het gebied van gedragsverandering wordt de bestuurskunde een design science (Simon, 1996; Barzelay \& Thomson, 2010; Moynihan, 2018), een wetenschappelijk vakgebied dat de praktijk helpt om maatschappelijke problemen aan te pakken.

\section{Literatuur}

Barzelay, M., \& Thompson, F. (2010). Back to the future: Making public administration a design science. Public Administration Review, 70, s295-s297. 
Bovens, M., Hart, P. 't, Twist, M.J.W. van, Berg, C. van den, Steen, M. van der, \& Tummers, L.G. (2017). Openbaar bestuur - Beleid, organisatie en politiek. Alphen aan den Rijn: Wolters Kluwer.

Bronkhorst, B., Tummers, L.G., \& Steijn, B. (2018). Improving safety climate and behavior through a multifaceted intervention: Results from a field experiment. Safety Science, 103, 293-304.

Egeberg, M. (1994). Bridging the gap between theory and practice: The case of administrative policy. Governance, 7(1), 83-98.

Engen, N.A.M. van. (2017). A short measure of general policy alienation: Scale development using a 10-step procedure. Public Administration, 95(2), 512-526.

Gallese, V., \& Goldman, A. (1998). Mirror neurons and the simulation theory of mind-reading. Trends in Cognitive Sciences, 2(12), 493-501.

Goldstein, D.G., \& Gigerenzer, G. (2011). The beauty of simple models: Themes in recognition heuristic research. Judgment and Decision Making, 6(5), 392-395.

Grimmelikhuijsen, S.G., Jilke, S., Olsen, A.L., \& Tummers, L.G. (2017). Behavioral public administration: Combining insights from public administration and psychology. Public Administration Review, 77(1), 45-56.

Hallsworth, M., Chadborn, T., Sallis, A., Sanders, M., Berry, D., Greaves, F., ... \& Davies, S.C. (2016). Provision of social norm feedback to high prescribers of antibiotics in general practice: A pragmatic national randomised controlled trial. The Lancet, 387(10029), 1743-1752.

Hallsworth, M., List, J.A., Metcalfe, R.D., \& Vlaev, I. (2017). The behavioralist as tax collector: Using natural field experiments to enhance tax compliance. Journal of Public Economics, 148, 14-31.

Hemerijck, A. (2003). Vier kernvragen van beleid. Beleid en Maatschappij, 30(1), 3-19.

Hood, C. (1991). A public management for all seasons? Public Administration, 69(1), 3-19.

Iacoboni, M. (2009). Imitation, empathy, and mirror neurons. Annual Review of Psychology, 60, 653-670.

Jachimowicz, J., Duncan, S., Weber, E.U., \& Johnson, E.J. (2019, in press). When and why defaults influence decisions: A meta-analysis of default effects. Behavioral Public Policy.

Kalse, E. (2019). Verkoop dure elektrische auto's stort in. NRC Handelsblad. Verkregen van https://www.nrc.nl/nieuws/2019/02/05/verkoop-dure-elektrische-autos-stort-ina3652943

Kuipers, B.S., Higgs, M., Kickert, W., Tummers, L.G., Grandia, J., \& Voet, J. van der. (2014). The management of change in public organizations: A literature review. Public Administration, 92(1), 1-20.

March, J.G., \& Olsen, J.P. (1989). Rediscovering institutions: The organizational basis of politics. New York: Free Press.

Moynihan, D. (2018). A great schism approaching? Towards a micro and macro public administration. Journal of Behavioral Public Administration, 1(1), 1-8.

Noordegraaf, M., \& Steijn, A.J. (Eds.). (2014). Professionals under pressure: The reconfiguration of professional work in changing public services. Amsterdam: Amsterdam University Press.

Ruyter, J.C. de, Olthof, M.R., Seidell, J.C., \& Katan, M.B. (2012). A trial of sugar-free or sugar-sweetened beverages and body weight in children. New England Journal of Medicine, 367(15), 1397-1406.

Simon, H.A. (1955). A behavioral model of rational choice. The Quarterly Journal of Economics, 69(1), 99-118. 
Simon, H.A. (1978). Rational decision-making in business organizations. Nobel Prize lecture. Retrieved from http://www.nobelprize.org/nobel_prizes/economicsciences/laureates/ 1978/simon-lecture.pdf

Simon, H.A. (1996). The sciences of the artificial (3rd ed.). Cambridge, MA: MIT Press.

Thaler, R.H., \& Sunstein, C.R. (2008). Nudge: Improving decisions about health, wealth, and happiness. New Haven, CT: Yale University Press.

Tummers, L.G. (2012). Policy alienation of public professionals: The construct and its measurement. Public Administration Review, 72(4), 516-525.

Tummers, L.G., Olsen, A.L., Jilke, S., \& Grimmelikhuijsen, S.G. (2016). Introduction to the virtual issue on behavioral public administration. Journal of Public Administration, Research \& Theory, 1-3.

Warburton, D.E., Nicol, C.W., \& Bredin, S.S. (2006). Health benefits of physical activity: The evidence. Canadian Medical Association Journal, 174(6), 801-809.

Willis, L.E. (2013). When nudges fail: Slippery defaults. The University of Chicago Law Review, 1155-1229. 